\title{
Corporatism and Economic Performance
}

\author{
Fredrik CA Andersson* ${ }^{* \dagger}$ \\ Department of Economics, Lund University
}

December 19, 2000

\begin{abstract}
A bstract
This paper models corporatism as affecting both the preferences of the parties involved as well as the rules of the game. The analysis is conducted in a uniongovernment game on determining wages and unemployment benefits. The result indicates that international conditions might be important for the functions of the concept of corporatism. It may also serve as an explanation to the poor performance on production and employment in some of the former so successful European corporatist states in the 1990s. The implication of this is that corporatism might not be a successful social organisation in the globalised economy.
\end{abstract}

J EL classifications: J32; J51

K eywords: Corporatism; Interest groups; Labour unions

*Department of Economics, Lund University, P.O.Box 7082, SE-22007 Lund, Sweden; Fax: +46 46 22241 18; e-mail: Fredrik_CA.Andersson@nek.lu.se

$\dagger$ I would like to thank Carl-Johan Belfrage, Hans Carlsson, Joakim Gullstrand, Göte Hansson, Hanna Norberg and participants in seminars at Lund University for useful suggestions and comments. Financial support from Sparbankernas Forskningsstiftelse, the Knut and Alice Wallenberg Foundation, the Royal Swedish Academy of Sciences, and the Crafoord Foundation is gratefully acknowledged. 


\section{Introduction}

The need for the trade unions and the industry to take responsibility in governing the economy has been put on the forefront of the agenda by politicians in a number of European states lately. An example is the establishment of a social pact between the government, the trade union confederation, and the central private employer's confederation in Italy, in December 1998. In Sweden negotiations between the trade union confederation and the central employer's confederation on forming an alliance for growth have been encouraged by the government, which also appointed former prime minister Ingvar Carlsson as mediator, in March 1999 (Svenska Dagbladet, 1999). It seems like these actions seek to restore the concept of corporatism as means to govern the domestic economy, and to be able to cope with changes in the international economic environment.

The picture on economic performance in the small European states from the 1950 is however not clear, as pointed out in Burda (1997). These states where corporatist structures have been pointed out as an effective social organisation, by both political scientists e.g. Katzenstein (1985) and economists e.g. Calmfors and Driffill (1988) performed relatively well up to the mid 1980s. However, since then the small European states have shown different patterns, especially in the 1990s. Examples are Finland and Sweden showing that the corporatist system is not immune against persistent and high unemployment rates, while other corporatist states as Austria and Norway have continued to perform relatively well and experienced low unemployment rates. The present model, which is an extension of the Burda (1997) model of corporatist and non-corporatist behaviour, shows that corporatism could be a successful social organisation in a stable economic environment, but in a volatile economic environment this need not be the case. The study thus indicates an explanation to why these differences may appear.

\subsection{The Concept of Corporatism}

The concept of corporatism has several definitions in the political science literature, e.g. Schmitter (1974), Wilensky (1976), Schmidt (1982), Lehmbruch (1984), and Lewin (1994). In a, by political scientists, frequently quoted study Katzenstein (1985) argued that the small European states with corporatist features were more successful and flexible to international changes than states with weak corporatist structures. Katzenstein (1985) defines corporatism as a form of social partnership between the government and centralised interest groups, as actors, who voluntarily and informally coordinate conflicting objectives. It is also argued that during periods when the domestic economy is under 
the pressure of some exogenous shock the voluntary coordination is most frequent. The above stated definition is, as argued in Hansson (1990), consistent with Olson's (1982) theories on encompassing organisations. Olson (1982) argued that "encompassing organizations have some incentive to make the society in which they operate more prosperous, and an incentive to redistribute income to their members with as little excess burden as possible, and to cease such redistribution unless the amount redistributed is substantial to the social cost of the redistribution."

In economics formal models describing the economic impact of corporatism are rare, as noted by for instance Bruno and Sachs (1985), Booth (1995) and Burda (1997). Most studies have focused on how wage structures on the macroeconomic level are affected by various degrees of centralisation in wage bargaining, e.g. Calmfors and Horn (1986), Tarantelli (1986), Calmfors and Driffill (1988), Layard (1991), Mulder (1993), and Booth (1995). These studies have tended to define corporatism as centralised wage bargaining. In a frequently cited study, Calmfors and Driffill (1988) hypothesise a hump shaped relationship between the degree of corporatism and the real wage.

In an empirical oriented study, Pekkarinen et al. (1992) analyses the impact of corporatism on various areas in the economy. Corporatism in their study is characterised by two basic features. First, the centralised wage bargaining. Second, the non-exclusive and egalitarian nature, i.e. the non-exclusion of any social group from the labour market, and sharing both the benefits of increasing economic welfare and the miseries of recession and the burden of adjustment. This definition is closer to the one used earlier in political science.

Burda (1997) defines corporatism as "measures which improve upon noncooperative interactions between union and government". This definition is closer to the one used by Katzenstein (1985) and Pekkarinen et al. (1992) than definitions used in earlier economic theoretical studies. Burda's (1997) analysis is conducted within a game theoretical framework, where a monopoly union formulates its' wage demands regarding the unemployment benefit level as given. In a self-financing system any additional unemployment will have negative budgetary implications and requires an increase in labour taxation and labour costs. Furthermore, the government determines the unemployment benefit level to maximise some social objective function given the level of wages, its actions will influence the process of wage formation. Burda (1997) argues that this interdependence implies that the Cournot/Nash equilibrium can be improved upon, i.e. in the corporatist economy the solution is cooperative. The basic results are that yet welfare improving for the parties involved the effects on wages and unemployment benefit levels are ambiguous. 


\subsection{M odelling Corporatism}

The present study shows that, focusing on arguments in political science on the functions of corporatism, a model of the type specified by Burda (1997) yields results that can be interpreted that corporatism is a successful social organisation in a stable economic environment, yielding lower wage rates and hence a higher level of production. On the other hand, when the economic environment is more volatile and the domestic economy is in stress and/or under the extent of exogenous economic shocks the results are ambiguous. These results emanates from the fact that, as argued by e.g. Lehmbruch (1982) and Katzenstein (1985), cooperation in the corporatist economy is a form of crisis management. Hence, the agents do not cooperate all the time in the corporatist economy, which they are assumed to do in the Burda (1997) model, but only when the economy is in stress. For example Lehmbruch (1982) argues that "corporatist incomes policies have mostly been a sort of crisis management where, under economic stress, the organisations have been ready to cooperate" (my italics). The rationale for this could be pure political. Towards the union members the leaders of the union wants to be able to show independence from the government, otherwise they risk to be connected with impopular political decisions. In the same manner to keep its credibility the government must be careful not to be too much connected with a single interest group such as a monopoly trade union. Furthermore, focusing on Katzenstein's (1985) definition of corporatism where social partnership is a central feature, it seems reasonable to argue that because of deliberative processes the corporatist union takes a broader social interest than a non-corporatist union. Thus, to stylise this the Burda (1997) model is extended in two ways, both in the objectives and in the rules of the game. First, the corporatist and non-corporatist trade unions have different objective functions. Besides the motivation above, a possible explanation for this is that the government allows the corporatist union to take part in political decisions if they act with social responsibility; here modelled as incorporating the interests of capital owners into the unions' decisions. This inclusion could also be seen to be in accordance with Olson's (1982) theories on encompassing organisations. According to Olson these organisations are so broad that they have difficulties in separating the social interest from the own group's interest. Thus the objective function of the corporatist union is similar, and in an extreme case identical, to the government's objective function. Second, by assumption cooperation between the government and the trade union only occurs in the corporatist economy, and only when the economy is in stress or exposed to exogenous shocks. This is as stated above in 
accordance with the arguments by e.g. Lehmbruch (1982) and Katzenstein (1985) that the coordination between the parties is intensified when the economy is in stress or under the extent of some exogenous shock.

The paper is organised as follows. Section 2 describes the economic environment and the agents of the model. Section 3 describes and discusses possible strategies for the union and the government. In section 4 different equilibria are analysed and discussed. The main results of the model are that a corporatist economy, compared with a non-corporatist economy has persistently lower wages in a stable economic environment, ceteris paribus. Furthermore, cooperation between the government and the trade union leads to ambiguous changes in wages and unemployment benefits, implying ambiguous results in employment and hence in the level of aggregated production, thus indicating that the corporatist economy might not be a successful concept in a volatile economic environment. Finally, section 5 concludes the study, and relates the results to earlier literature and to empirical observations in the time period from the 1950s.

\section{Economic and Political Structure}

Consider an economy with three types of agents, the monopoly union, the firms, and the government. The union decides the net wage level, $w$, and the government chooses the unemployment benefit level, $b$. The level of taxation, $\tau$, is endogenously determined to balance the governmental budget. Given the gross wage the firm then choose how much labour to employ, $n$, in this model expressed as a fraction of the labour force which is normalized to unity.

This behaviour can be seen as a game between two players, the union and the government, with full information on the game choosing the net wage level, $w$, and the unemployment benefit level, $b$, respectively under the restriction that the government balances its' budget.

\subsection{The Firm}

The representative firm maximises its profits $\pi$, subject to a given world market price level, $p$, normalised to unity, and the gross wage rate, $w(1+\tau)$, where $\tau$ is the tax rate endogenously determined by the government budget constraint.

$$
\pi=f(n)-w(1+\tau) n
$$


where

$$
y=f(n) \quad f^{\prime}>0, f^{\prime \prime}<0
$$

$y$ is the aggregated output of the firm and $f(n)$ the aggregated production function, showing diminishing returns in the production input labour, $n$. Other production inputs such as capital are not explicitly shown in the model since they by assumption are held constant. The maximum level of production in the economy is reached when the economy is in the state of full employment. The firm's wage costs are linear in labour input and gross wages.

Profit maximisation implies convex labour demand for the firm in gross wages, $w(1+\tau)$

$$
n=g(w(1+\tau))
$$

where $g^{\prime}<0$, since $f(n)$ is concave.

\subsection{The Trade Union}

The monopoly union represents a fraction $\lambda$ of the economy's employed labour force. The union is assumed to decide the real net wage, $w$, and the firm employs a fraction $n$ of the economy's labour force, according to the labour demand function specified in equation (3). The union is assumed to chose a wage rate, $w$, in order to maximise an objective function ${ }^{\mathrm{i}} \Omega^{U} \bar{\phi}$ given government behaviour. An approach to represent union preferences in utilitarian objective functions are known from e.g. McDonald and Solow (1982), Oswald (1982, and 1985), and Burda (1997). However, in our model we work with an extension of the utilitarian objective function where the level of aggregated production is included. This function can be seen to represent the preferences of the union leaders. They are assumed to seek to stay in power of the union, which requires a sufficiently high level of utility for the members. Furthermore, they seek to maximise union power, which requires a sufficiently high member rate, and hence a low degree of unemployment. The objective function is specified as:

$$
\Omega^{U}=\lambda n u(w)+\alpha(n-\lambda n) u(w)+\beta(1-n) u(b)+\gamma y
$$

where $u(w)$ represents utility levels for employed members and non-members and $u(b)$ represents the utility of the unemployed. Assume $u^{\prime}>0$ and $u^{\prime \prime}<0$. The parameters $\alpha, \beta \in(0,1]$ are relative utility weights assigned by the union to non-member employed and unemployed, respectively. Parameter $\gamma>0$ is the relative weight assigned the level of aggregated production in the economy, $f(n)$. The corporatist union assigns the level of 
production positive weight, i.e. $\gamma>0$. The non-corporatist union sets $\gamma=0$. It should be noted that when $\gamma=0$ and the union member rate is exogenously given, the objective function is identical to the one specified in Burda (1997).

The inclusion of the level of production, i.e. $\gamma>0$, in the objective function could be motivated by the assumption that the government gives the corporatist union the opportunity to take part in governing the economy only if they take a broad social interest. The inclusion is also in accordance with the theories by Olson (1982) on encompassing organisations. The encompassing organisation represents an interest group of a size large enough making it difficult to separate the interests of the own group from the public interest. It can also be seen as an effect of deliberative processes. Frequent contacts between the government and the trade union makes them more aware of each other's problems.

\subsection{The Government}

The government seeks to stay in power. In order to do so it is assumed to balance the utility of different interest groups and the level of aggregated production. The objective function of the government to be maximised is

$$
\Omega^{G}=n u(w)+(1-n) u(b)+\delta y
$$

The government weights the utilities of employed and unemployed equally. The government also assigns a weight $\delta>0$ on aggregated output in the economy. If $\delta=\gamma$, which can be the case when close contacts exists between the government and the corporatist union, and $\alpha=\beta=1$ the government and the corporatist union have identical objective functions. If $\delta=0$, and $\alpha=\beta=1$ the government and the non-corporatist union have identical objective functions.

The government chooses the level of unemployment benefits in order to maximise $\Omega^{G}$ taking $w$ as given and with respect to the demand function for labour, equation (3), and a budget constraint implying that the sum of unemployment benefits must be financed with taxes.

$$
\tau w n=(1-n) b
$$

A binding budget constraint implies that the government can not choose both $\tau$ and $b$; consequently $\tau=(b / w)\left(n^{-1}-1\right)$. The existence of an equilibrium tax rate is determined by the labour demand function. Assuming that non-trivial solutions exist, of which the minimum tax rate is chosen, we analyse what conditions must be fulfilled in equilibrium. 
The labour demand function (3) has the following properties $n \in(0,1), \frac{\partial n}{\partial \tau}=w g^{\prime}<0$, and $\frac{\partial^{2} n}{\partial \tau^{2}}=w^{2} g^{\prime \prime}>0$, i.e. convex in $\tau$. To avoid trivial solutions, assume that $g(w, 0) \leq 1$, i.e. unemployment exists when the labour taxation is zero. Furthermore, the inverse of the government budget constraint implies that, in equilibrium, labour demand must satisfy

$$
n=h(\tau, w, b) \equiv{ }^{3} \frac{\tau w}{b}+1^{-1} .
$$

Where $h(0, w, b)=1$ and $\lim _{\tau \rightarrow \infty} h(\cdot)=0$. Contemplating $g(\tau, w)$ and $h(\tau, w, b)$ in $(n, \tau)$ space, at the equilibrium tax rate the demand for labour must equal the inverse budget constraint i.e. $g(\tau, w)=h(\tau, w, b)$. Furthermore, at the minimum equilibrium tax rate the labour demand function crosses the inverse budget constraint from below, i.e. $\frac{\partial g}{\partial \tau}>\frac{\partial h}{\partial \tau}$, that is

$$
g^{\prime} w>-{ }^{3} \frac{\tau w}{b}+1^{-2} \frac{w}{b} .
$$

Which in equilibrium can be rewritten as

$$
-b g^{\prime} g^{-2}<1
$$

Consequently, a necessary condition at the minimum equilibrium tax rate is that

$$
-b g^{\prime} g^{-2}<1, \text { and } g={ }^{3} \frac{\tau w}{b}+1^{\prime}{ }^{-1} .
$$

This implies that for all production functions $f$, that imply labour demand functions $g$ that fulfills condition (10), at least one equilibrium tax rate exists. Clearly the production function sets the range of possible wage rates, $w$, and unemployment benefit levels, $b$, that generates equilibrium. The unemployment benefit level is limited upwards, $b<-\frac{g^{2}}{g^{0}}$.

Furthermore, under the existence of an equilibrium tax rate, equation (3) yields $n=$ $g\left(w+b\left(n^{-1}-1\right)\right)$, i.e. labour demand can be expressed as a function of net wages, $w$, and unemployment benefits, $b$. Both the government and the union are assumed to recognise the financial implications of an increase in unemployment benefits, $b$, on labour taxes, $\tau$. Both a greater fiscal burden of the existing unemployment stock and higher unemployment at given unemployment benefit levels resulting from increased labour costs. Formally,

$$
\frac{\partial n}{\partial b}=g^{\prime}\left(g^{-1}-1\right) /\left(1+b g^{-2} g^{\prime}\right)<0 .
$$

Using a similar argument, the effect of a wage increase is

$$
\frac{\partial n}{\partial w}=g^{\prime} /^{\mathbf{i}} 1+b g^{-2} g^{\prime}<g^{\prime}<0 \text {. }
$$


Since the tax rate is endogenous in the model and we are interested in the actions taken by the union and the government who are regarded as completely informed, the elasticity of labour demand with respect to net wages, for a given $b$ and given the financial constraint (6) of the government can be defined as

$$
\eta=-\frac{\partial n}{\partial w} \frac{w}{n}
$$

which, following Burda (1997), for convenience is assumed to be constant.

\section{Strategies $^{1}$}

\subsection{The Trade Union's R eaction Function}

The optimal policy of a monopolist union taking the unemployment benefit level as given has been described by e.g. Oswald (1982, and 1985), and Burda (1997). The first order condition of the maximisation problem is:

$$
\frac{\partial \Omega^{U}}{\partial w}=\left[(1-\alpha) \lambda u+\alpha u-\beta \boldsymbol{e}+\gamma f^{\prime}\right] \frac{\partial n}{\partial w}+u^{\prime}[(1-\alpha) \lambda n+\alpha n]=0
$$

where, in order to shorten the expressions, $u$ is denoting utility of wages, i.e. $u=(w)$, and $\boldsymbol{\theta}$ is utility from unemployment benefits, i.e. $\boldsymbol{\Theta}=u(b)$. Using equation (13) the first order condition can be rewritten as:

$$
\begin{gathered}
w u^{\prime}[(1-\alpha) \lambda+\alpha]-\eta\left[(1-\alpha) \lambda u+\alpha u-\beta \boldsymbol{e}+\gamma f^{\prime}\right]=0 \\
\Leftrightarrow \\
{[(1-\alpha) \lambda+\alpha] \frac{u^{\prime} w}{\left((1-\alpha) \lambda u+\alpha u-\beta \mathbf{e}+\gamma f^{\prime}\right)}=\eta}
\end{gathered}
$$

implying that the union sets the wage so that the elasticity of a utility gain in employment from an increase in the net wage is equal to the elasticity of labour demand. When $\gamma=0$, and the member rate in the union is exogenously given this condition is identical to the result derived in the Burda (1997) model. Furthermore if $\gamma=0$ and $\alpha=\beta=1$, the condition is analogous to the results derived by McDonald and Solow (1981), Oswald (1982), and Booth (1985).

The net wage, $w$, set by the union depends on the unemployment benefit level, $b$, i.e. the union strategy is a function of the unemployment benefit level set by the government,

\footnotetext{
${ }^{1}$ An appendix with further mathematics is avilable upon request from the author.
} 
$w=w(b)$. In order to analyse the strategy, note that the evolution of union utility in $b$, is ambiguous, since the sign of $\partial \Omega^{U} / \partial b=-[(1-\alpha) \lambda+\alpha](1-n) u^{\prime}+\beta(1-n) \boldsymbol{e}^{\prime}$ depends on the size of parameters $\alpha, \beta, \lambda$, and the marginal utilities. This implies different possibilities for the form of the preferences. They may be ever increasing or decreasing in $b$, or both. Where the latter implies bliss point preferences.

Furthermore, following Oswald (1982), and Burda (1997), the slope of the reaction function, representing the union strategy, can be determined using the implicit function theorem, evaluating $\frac{d w}{d b}=-\frac{\partial^{2} \Omega^{U}}{\partial w \partial b} / \frac{\partial^{2} \Omega^{U}}{\partial w^{2}}$. If the second order condition

$$
\frac{\partial^{2} \Omega^{U}}{\partial w^{2}}=u^{\prime \prime}[(1-\alpha) \lambda+\alpha] \frac{w}{\eta}+u^{\prime}[(1-\alpha) \lambda+\alpha] \frac{1}{\eta}-u^{\prime}[(1-\alpha) \lambda+\alpha]-\gamma f^{\prime \prime} \frac{\partial n}{\partial w}<0
$$

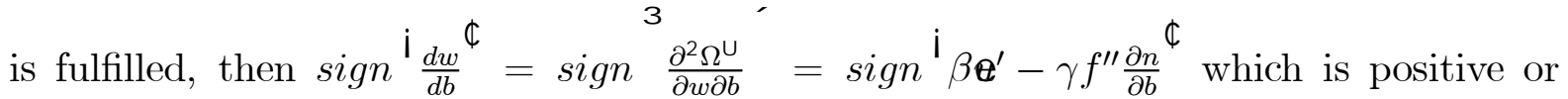
negative depending on the size of the weight $\gamma$ put on the level of aggregated production, i.e. the slope of the reaction function is of ambiguous sign. Note that if $\gamma=0$, implying a non-corporatist union, the reaction function is unambiguously positively sloped. A sufficient condition for the second order condition (17) to be fulfilled is that the coefficient of relative risk aversion exceeds 1 , that is $-\frac{u^{\omega_{w}}}{u^{0}}>1$. It is possible to graphically represent the union preferences and implied reaction function as depicted in Figure 1. Note that

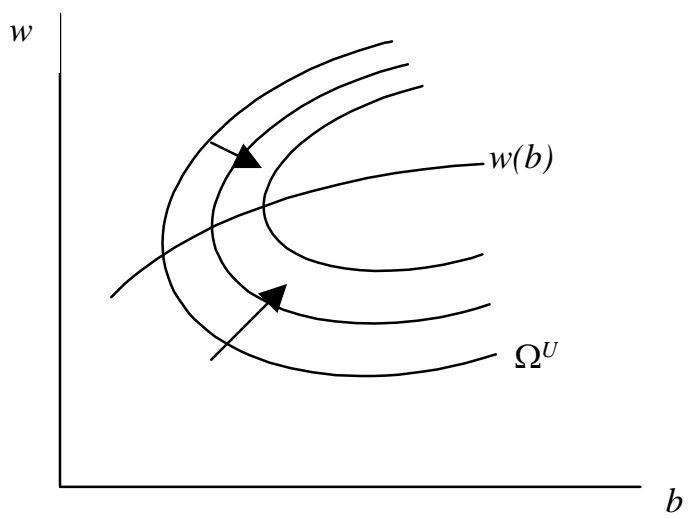

Figure 1: Union preferences and possible reaction function.

there are several possibilities to graphically represent combinations of preferences and the reaction functions of different slope. However, as will be seen later the slope of the union's reaction function has no implications for the results of the model. This is also the case for the bliss point preferences. 
Comparing strategies for the corporatist and the non-corporatist unions there will obviously be a difference in the chosen strategy. The corporatist union will always, ceteris paribus, respond with a lower wage rate, $w$, to a given unemployment benefit level, $b$, than the non-corporatist union. The reason is that the objective function of the corporatist union contains the aggregated level of production in the economy, $f(n)$, with properties $\frac{\partial f}{\partial w}=\frac{\partial f}{\partial n} \frac{\partial n}{\partial w}<0$. Hence, the reaction function of the corporatist union is pushed down to the right in $(w, b)$ space. The reaction functions representing the strategies of the two different types of unions are presented in Figure 2.

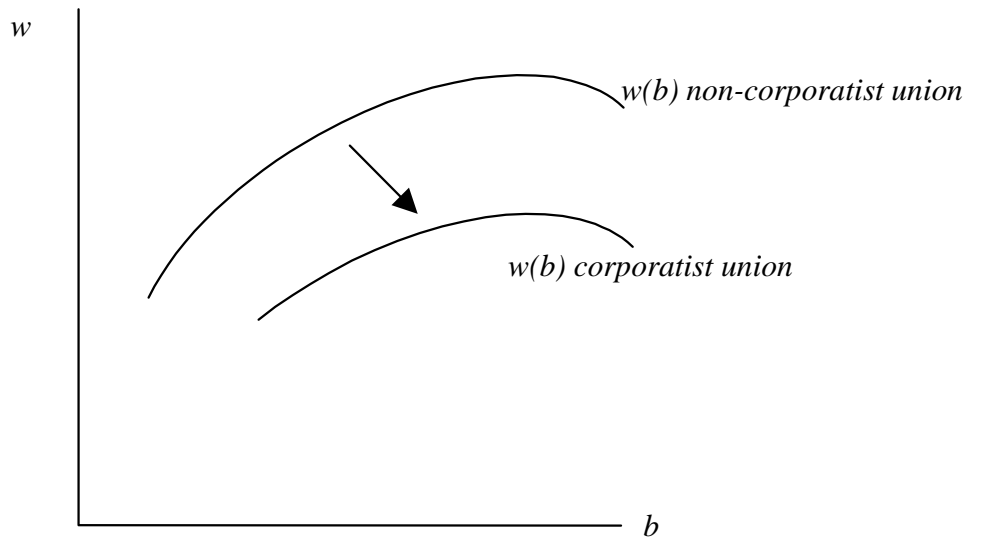

Figure 2: Reaction functions for corporatist respective non-corporatist unions.

\subsection{The Government's R eaction Function}

The government maximises the objective function (5) under the budget restriction (6). The first order condition gives

$$
\frac{\partial \Omega^{G}}{\partial b}=\left[u-\boldsymbol{e}+\delta f^{\prime}\right] \frac{\partial n}{\partial b}+(1-n) \boldsymbol{e}^{\prime}=0
$$

Use the fact that equations (11) and (12) implies that $\frac{\partial n}{\partial b}$ can be written as

$$
\frac{\partial n}{\partial b}=\frac{\partial n}{\partial w}\left(g^{-1}-1\right)
$$

This allows us to rewrite the first order condition (18) using equation (19) and the definition of the elasticity of labour demand (13) as

$$
\frac{\partial \Omega^{G}}{\partial b}=-\eta\left[u-\mathbf{e}+\delta f^{\prime}\right]+w \boldsymbol{e}^{\prime}=0 .
$$


The unemployment benefit level, $b$, set by the government depends on the net wage rate, $w$, decided by the union, i.e. government strategy can be represented in a reaction function of the form $b=b(w)$.

In order to further analyse the government strategy, first note that the sign of $\partial \Omega^{G} / \partial w=$ $n u^{\prime}+\left[u-\mathbf{e}+\delta f^{\prime}\right](\partial n / \partial w)=n\left(u^{\prime}-\tilde{u}^{\prime}\right)$ is depending on which marginal utility that dominates along the reaction function. Thus, the evolution of government utility in $w$ is of ambiguous sign. Furthermore, the implicit function theorem states that the slope of the government's reaction function is given by $\frac{d b}{d w}=-\frac{\partial^{2} \Omega^{\mathrm{G}}}{\partial b \partial w} / \frac{\partial^{2} \Omega^{\mathrm{G}}}{\partial b^{2}}$. Using the same logic as for the union, if the second order condition is fulfilled, which requires $\frac{\mathbf{e}^{\omega_{w}}}{\mathbf{e}^{0}}>\eta$, then the sign of $\frac{d b}{d w}$ is that of

$$
\frac{\partial^{2} \Omega^{G}}{\partial b \partial w}=-\eta u^{\prime}-\eta \delta f^{\prime \prime} \frac{\partial n}{\partial w}+\mathbf{e}^{\prime}
$$

where $\frac{\partial n}{\partial w}<0$, which is defined in equation (12). The sign of equation (21) is ambiguous, depending on the weight, $\delta$, put on the level of production, $f(n)$ and on the relative levels of marginal utilities, $u^{\prime}$ and $\tilde{u}^{\prime}$.

The above stated implies that in some unrestricted sense the government exhibits bliss point preferences. The argument for bliss point preferences is increased if as in Burda (1997) it is assumed that $u$ and $\tilde{u}$ represents different utility functions where $\tilde{u}^{\prime}>u^{\prime}$. Furthermore, this certifies that the bliss point is in the feasible range of the strategy set if the government imposes the restriction $b \leq w$, i.e. the unemployment benefit level can never exceed the wage rate. The bliss point preferences for the government arises since it might exist a trade off between two wage rates that results in the same value on the objective function at a constant unemployment benefit level. These preferences imply either positively or negatively sloped reaction functions depending on the relative weights in the government objective function. In Figure 3 some possible indifference maps, with implied reaction functions have been depicted. Later, in the analysis of different possible equilibria we focus on two different cases one where higher and one where lower wage rates are preferred by the government.

\section{Equilibria}

The monopoly union and the government are now regarded as two players in a game. The strategy set for the union is the set of different wages it can choose. The government's set of strategies is the set of possible unemployment rates it can choose. The payoff for each player is influenced of both players' choice of strategy. 

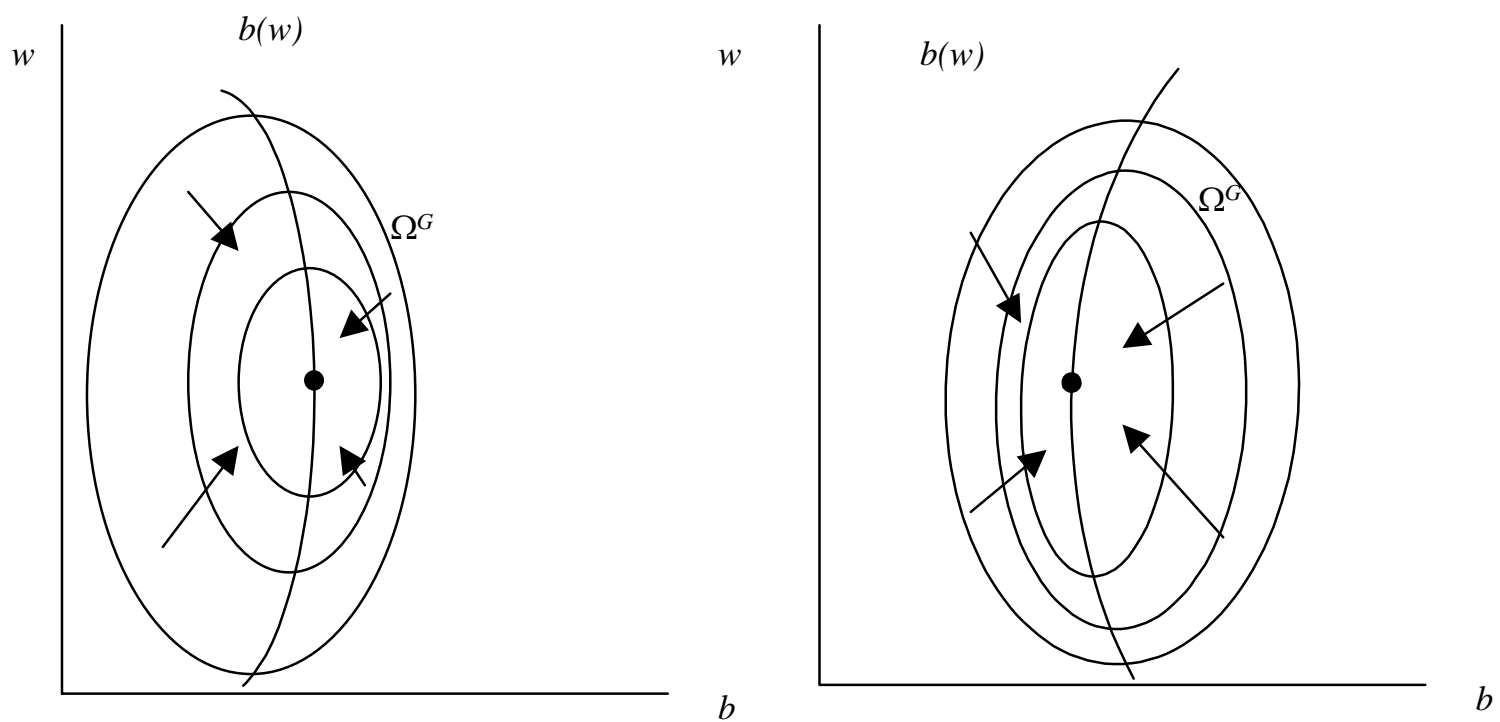

Figure 3: Government preferences and implied reaction functions.

The preferences of the union and the government yield a number of possible equilibria depending on the characteristics of the player's preferences. We will analyse two types of equilibria emanating from whether the government prefer increasing (Figure 4 a) or decreasing (Figure $4 \mathrm{~b}$ ) wage rates. This because these two cases yields contradictory results on unemployment and production. Figure 4 describing a non-corporatist economy shows preference maps $(\Omega)$ and reaction functions $(w(b)$ and $b(w))$ for the government $(G)$ and the non-corporatist union $(U)$ respectively. For simplicity the reaction functions are drawn as straight lines, but may as shown before be nonlinear.

The intersection of the reaction functions represents the Nash-Cournot equilibrium $(A)$ with $\left(w_{A}\right.$ and $\left.b_{A}\right)$. The Stackelberg solution is determined by a player selecting the value of the decision variable which maximises his objectives against the opponent's reaction function. The Stackelberg solution with the government as leader is denoted $(S G)$ with $\left(w_{S G}\right.$ and $\left.b_{S G}\right)$ and with the union as leader $(S U)$ with $\left(w_{S U}\right.$ and $\left.b_{S U}\right)$. As can be seen in Figure 4 the differences between the Stackelberg solution and the Nash-Cournot solution depends both on the characteristics of the preferences and on who is the leader. If the government is acting as the leader in Figure 4 a) it implies what Burda (1997) calls a "rigorous" policy, inferior to the union. While Figure $4 \mathrm{~b}$ ) shows the possibility of a policy which is welfare improving for both parties. The results so far are identical with the findings in Burda (1997). Although it could be argued that this game must not be 
a)

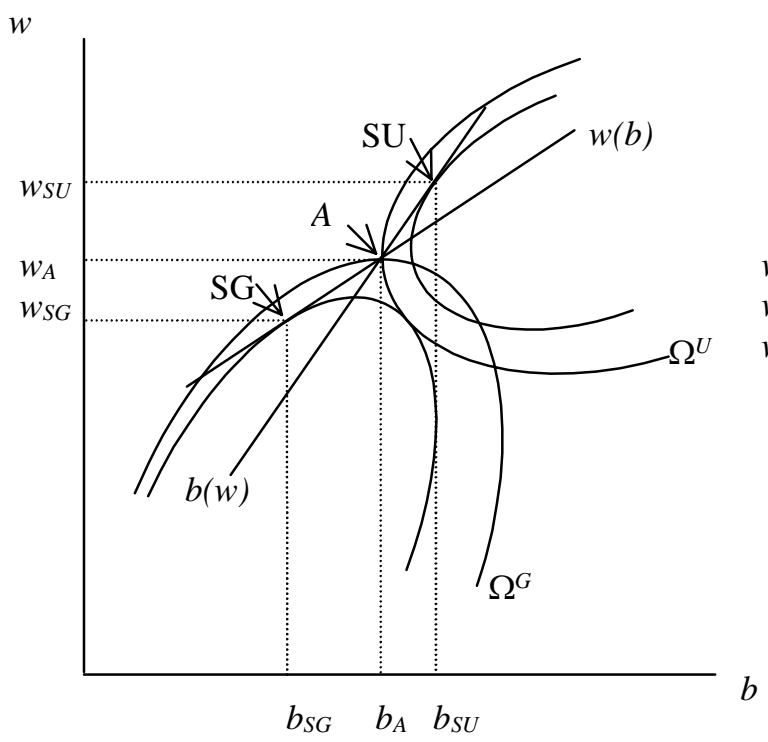

b)

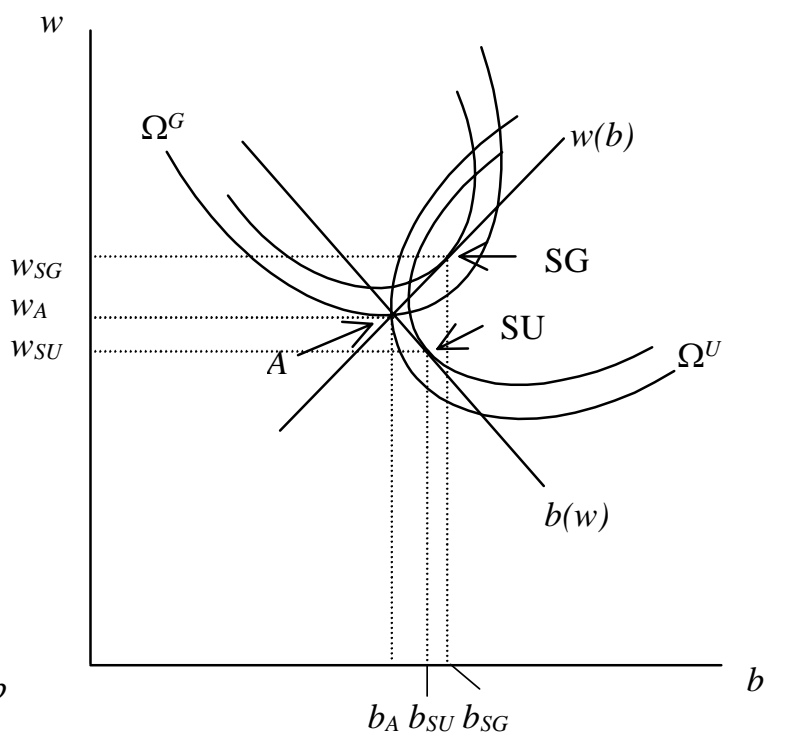

Figure 4: Nash-Cournot equilibrium (A) and Stackelberg equilibria (SG and SU) with different preference maps for the government $(\mathrm{G})$ and the union $(\mathrm{U})$.

simultanous and that a Stackelberg game implies different solutions than a simultaneous game with the Nash-Cournot solution this has no implication for our results. Hence, in the following we assume the game to be simultaneous.

Now turn to the corporatist economy. Here, as argued above, the difference between the corporatist and non-corporatist unions are shown in the preference sets. The corporatist union has a different objective function compared to the non-corporatist union, where the former type of union takes a broader social interest than the later. This has, as shown earlier, an effect on the strategy set of the corporatist union. Ceteris paribus the optimum wage rate for the corporatist union is lower than for the non-corporatist union. This results in a lower Nash-Cournot equilibrium $(B)$ for in the corporatist economy, as shown in Figure 5. Note that the relation between equilibria $(A)$ and $(B)$ is independent of what type of preferences the player have. All possible types of preferences discussed above yields the same result.

As shown in Figure 5 the corporatist economy always exhibits a lower wage rate than the non-corporatist economy. Furthermore, Katzenstein (1985) argues that the coordination of conflicting objectives between interest groups and the government is strongest when the economy is in stress or under the extent of an exogenous shock, a phenomena 
a)

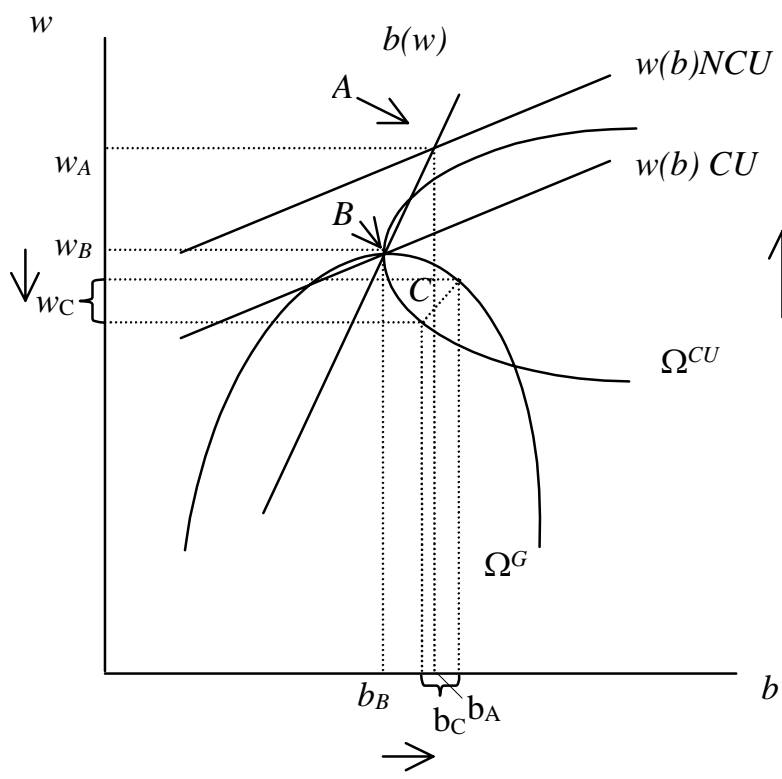

b)

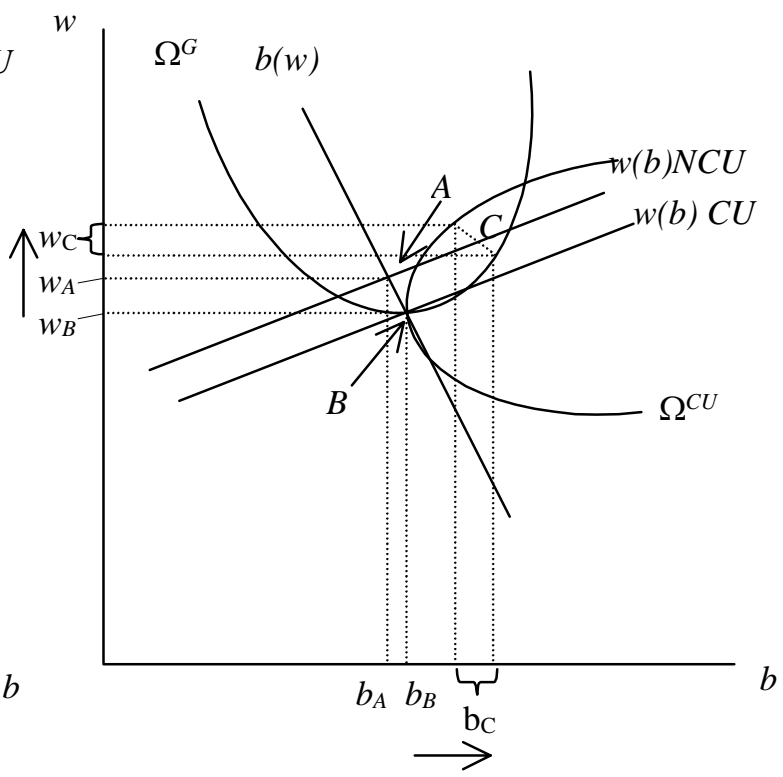

Figure 5: Different equilibria: non-corporatist (A), corporatist (B), and corporatist cooperative equilibrium $(\mathrm{C})$.

also observed by Lehmbruch (1982). Hence there are two types of equilibria in corporatist economies, not only the Nash-Cournot equilibrium $(B)$ but also a cooperative equilibrium $(C)$ somewhere on the contract curve (the dotted line in Figure 5). To keep the analysis as simple as possible we focus on a situation where the economy is in stress, i.e. we assume that the level of aggregated production have not changed, which otherwise would give shifts in all curves in the figure. Note however that this would not change the results from the analysis, it would only complicate the figures.

If the corporatist economy is under stress, then by assumption, the union and the government starts to cooperate. As illustrated in Figure 5 the results from cooperation between the corporatist union and the government is however ambiguous. Yet welfare improving for the parties involved the evolution of wages and unemployment benefit levels are depending on the location of the bliss points and the slope of the government reaction function. Note the possibility that in the cooperative equilibrium wages can be even higher than in the non-corporatist economy. Hence, ceteris paribus the corporatist economy can show higher unemployment rates and lower production rates compared to the non-corporatist economy. Thus the results from the analysis can be stated as:

In a stable economic environment an economy with a corporatist social organisation 
compared to a non-corporatist economy yields lower wage rates and hence lower unemployment rates and higher levels of aggregated production, ceteris paribus.

In a more volatile economic environment, where the domestic economy is in stress, the result of a corporatist social organisation is ambiguous.

\section{Concluding Remarks}

This study analyses differences in aggregated production and unemployment in corporatist respective non-corporatist economies. In the model the corporatist union is defined as taking broader social interest than the non-corporatist union. Furthermore, in the corporatist economy the government and the trade union, by assumption based on arguments by political scientists e.g. Lehmbruch (1982) and Katzenstein (1985), have the possibility of cooperating when the economy is under stress or hit by an exogenous shock. With long-term wage contracts this structure implies that in a stable economic environment, on average, a new contract will be settled on the non-cooperative equilibrium. On the contrary, in a volatile economic environment, cooperation is frequent which implies that on average a new wage contract will be settled on the cooperative equilibrium wage rate.

In our model the results of corporatism is highly dependent on the economic environment. In periods of stability the wages in the corporatist economy tend to be lower compared to non-corporatist economies, with strong trade unions. The level of unemployment benefits in the corporatist economy relative non-corporatist economies is indeterminate. If the corporatist economy is in stress, then by assumption, cooperation between the government and the corporatist trade union appears. The cooperation turns out to be welfare improving for the parties involved but yield ambiguous results on unemployment benefits, wages and hence unemployment rates and the level of aggregated production.

This model extends the conclusions in Burda (1997) to be valid only in periods of volatility in the economic environment. Burda modelled corporatism as cooperation between the government and the union. This is welfare improving for the parties involved, but has few implications for the evolution of unemployment benefits, wages, and hence for the unemployment level. Furthermore, the result from our model of persistently lower wages in the corporatist economy under periods of stability in the economic environment, supports the hypothesis by Calmfors and Driffill (1988) of a hump shaped relationship between real wages and the degree of wage centralisation, where high degrees of wage 
centralisation is characterised as corporatism. However, this need not be the case in periods of volatility in the economic environment.

The results of the model can explain the poor economic performance in some of the former successful corporatist states. One central feature in corporatism is the centralised wage bargaining, and also the existence of social contracts. As a rule these contracts run over several years. Thus, in order to be successful an economy with long-term contracts requires stability. The economic environment during the 1950s up to the beginning of the 1970s can be characterised as fairly stable. The demand side were stable or increasing and production were growing. The financial markets were still regulated, preventing large capital flows between different states.

The problems in the corporatist states started in the 1970s with a combination of the oil crisis and the collapse of the exchange rate system as well as a stagnation or decline on the demand side and increased competition in important industries from e.g. newly industrialised countries, which accelerated in the 1980s. Add to this the technological development and use of information technology, and the deregulation of the financial markets around 1990. The increased interdependency between states together with the deregulations of important financial markets gives that the autonomous economy does not exist on national level any more. Then the international economic environment for the European corporatist states has completely changed. Thus this could be one reason why the corporatist states have problems because contracts on the national level do not have the same importance as earlier. It can even be that the corporatist structure is a problem in the domestic economy, because special interest groups are given strong power. This is argued in e.g. Jacobsson et al. (1999). Hence corporatism seems not a successful way to organise society in the globalised economy of today.

Studies in political science, e.g. Lewin (1992) have concluded that the corporatist structures have been fading out since the beginning of the 1980s. This might be explained by Stigler's (1971) capture theory. Stigler (1971) argues that corporatism undermines the position of organisations. The organisation's representatives in public authorities could easily be captured by the authority itself and become its' spokesman instead of supervisor undermining the core idea of corporatism. However, the results of the present model could serve as an alternative, or complementary, explanation to the phenomenon of declining corporatism. If the period from the 1980s can be characterised of instability compared to the period from the 1950s till the end of the 1970s then the decline of corporatism coincides with a period where there is cooperation in the corporatist states. As has been shown above this cooperation is welfare improving for the parties involved 
but can yield results not optimal for the economy as a whole. Hence, the situation is not sustainable. The reason is that in the new economic environment the special interest group seems to get disproportionate large power. In such cases the interest group seems to benefit on the cost of others in the economy and it is very hard for a trade union to be intimately connected with the government when the unemployment rate is increasing but wages for the employed at the same time increases.

The industry does not have an active role in the game in this model. Intuitively, allowing the owners of the firms to use a part of the profits for lobbying the government for a higher weight $\delta$ on the level of production in the government's objective function (5) this would shift the government preference map to the left in Figure 3. Consequently the government reaction function will be shifted to the left; thus implying lower unemployment benefit levels, reducing taxes and thus increasing employment. However, allowing for this would not have any implications on the results of the analysis of differences between corporatist and non-corporatist economies. The ambiguous results from cooperation in the corporatist economy would persist. 


\section{References}

Booth, A., 1995, The economics of the trade union (Cambridge University Press, Cambridge).

Bruno, M. and J. Sachs, 1985, The economics of stagflation (Harvard University Press, Cambridge, MA).

Burda, M.C., 1997, Wither Corporatism? Corporatism, labor unions and the safety net, European Economic Review 41, 635-646.

Calmfors, L. and J. Driffill, 1988, Bargaining structure, corporatism and macroeconomic performance, Economic Policy 6, 16-61.

Calmfors, L. and H. Horn, 1986, Employment policies and centralized wage setting, Economica 53, 281-302.

Hansson, G., 1990, Den internationaliserade ekonomins autonomi, in: G. Hansson, and L.-G. Stenelo, eds., Makt och internationalisering (Carlssons, Stockholm).

Jacobsson, U., L. Bergman, P. Braunerhielm, S. Fölster, and H. Genberg, 1999, Vägen till välstånd, Konjunkturrådets rapport (SNS Förlag, Stockholm).

Katzenstein, P. J., 1985. Small states in world markets, Industrial policy in Europe (Cornell University Press, Ithaca and London).

Layard, R., S. Nickell, and R. Jackman, 1991, Unemployment (Oxford University Press, Oxford).

Lehmbruch , G., 1982, European neo-corporatism: An export article?, Woodrow Wilson International Center Scholars, Colloquium Paper.

Lehmbruch , G. 1984, Concertation and the structure of corporatist networks, in: J. H. Goldthorpe, ed., Order and conflict in contemporary capitalism: Studies in the political economy of western European nations (Oxford University (Clarendon) Press, Oxford).

Lewin, L., 1992, Samhället och de organiserade intressena (Norstedts, Stockholm).

Lewin, L., 1994, The rise and decline of corporatism: The case of Sweden, European Journal of Political Research 26, 59-79. 
McDonald, I. and R. Solow, 1981, Wage bargaining and employment, American Economic Review 71, 896-908.

Olson, M., 1982, The rise and decline of nations. Economic growth, stagflation, and social rigidities (Yale University Press, New Haven and London).

Oswald, A., 1982, The micro-economic theory of the trade union, Economic Jounal $92(367), 576-95$.

Oswald, A., 1985, The economic theory of trade unions: An introductory survey, Scandinavian Journal of Economics 87(2), 160-93.

Pekkarinen, J., M. Pohjola, and B. Rowthorn, 1992, Social corporatism: A superior economic system? (Clarendon Press, Oxford).

Schmidt, M., 1982, The role of parties in shaping macroeconomic policy, in: F. G. Castles, ed. The impact of parties: Politics and policies in democratic capitalist states (Sage, London/Beverly Hills).

Schmitter, P. C., 1974, Still the century of corporatism?, The Review of Politics 36, 85-131.

Stigler, G., 1971, The theory of economic regulation, Bell Journal of Economics and Management Science (2), 3-71.

Svenska Dagbladet, March 16, 1999, Lönebildningen blir politisk fråga.

Tarantelli, E., 1986, The regulation of inflation and unemployment, Industrial Relations $25,1-15$.

Wilensky, H. L., 1976, The 'new corporatism', centralization and the welfare state (Sage, London/Bevely Hills). 